\title{
A INFLUÊNCIA DA FERROVIA E O CONTEXTO DÉCO
}

\author{
Letícia Perez Guedes
}

Universidade do Oeste Paulista - UNOESTE, curso de Arquitetura e Urbanismo, Presidente Prudente, SP. E-mail: leticiaperezguedes@hotmail.com

\section{RESUMO}

A presente pesquisa possui o intuito de demonstrar a importância das ferrovias para o surgimento de diferentes cidades do estado de São Paulo, demonstrando ainda, sua influência no contexto déco brasileiro. A metodologia para este trabalho embasou-se em levantamentos bibliográficos afim de demonstrar o advento do estilo art déco no Brasil, uma tendência extremamente difundida na década de 30 e 40 a qual se expressou em diversos âmbitos, como edificações, móveis, objetos, esculturas, pinturas, dentre outros. Em relação a arquitetura, o visual déco apresentou-se em inúmeras construções, no início expressando-se em projetos que procuravam explanar um mundo moderno, contudo, suas características fizeram-se presentes principalmente em edificações fabris.

Palavras-chave: Ferrovia, Brasil, São Paulo, Art Déco, Edificações Fabris.

\section{THE INFLUENCE OF THE RAILWAY AND THE DECO CONTEXT}

\begin{abstract}
The present research intends to demonstrate the importance of the railways to the emergence of different cities of the state of São Paulo, demonstrating also their influence in the Brazilian déco context. The methodology for this work was based on bibliographical surveys, readings and archives, in order to demonstrate the emergence of the Art Deco style in Brazil, an extremely widespread tendency in the 30's and 40's, which was expressed in several areas such as buildings, furniture, Objects, sculptures, paintings, among others. In relation to architecture, the visual déco appeared in numerous constructions, initially expressing itself in projects that sought to explain a modern world, however, its characteristics were mainly present in factory buildings.
\end{abstract}

Keywords: Ferrovia, Brazil, São Paulo, Art Déco, Fabris Buildings.

\section{INTRODUÇÃO}

Mesmo previamente a construção de ferrovias, as cidades brasileiras já se desenvolviam mais pela extensão de importantes caminhos de circulação do que em outras direções. A expansão dessas cidades sempre se deu ao redor de vias intermediadoras entre a região com a qual mantinham fluxos acentuado de tráfego, e a partir do surgimento das ferrovias esse fator se acentuou. (VILLAÇA, 2001).

Interesses econômicos aliados a facilidade de caminhos, que tornassem os mesmos viáveis, foram a combinação perfeita para o direcionamento do crescimento das cidades, bem como o fator principal para o surgimento de novos povoados. No estado de São Paulo, o surgimento da ferrovia teve ligação direta com a expansão cafeeira, a qual se estendeu para o oeste criando tentáculos atraentes a novos vilarejos e núcleos urbanos.

Segundo Matos (1990, p.42), as ferrovias produziam uma intensa movimentação, a qual era crescente, influenciando na troca de mercadorias, pessoas e informações, "[...] aos poucos dissolviam o arranjo dos espaços mais lentos, interagindo de forma mais intensa nos lugares, criando um novo tempo-espaço para uma sociedade mais moderna. " 
O objetivo deste estudo foi entender sobre como as ferrovias, o surgimento das cidades e a troca de informações influenciaram na difusão da tendência déco brasileira presente em edificações fabris que se instalavam ao longo das estações ferroviárias.

\section{METODOLOGIA}

A metodologia utilizada na presente pesquisa baseia-se em levantamentos bibliográficos, leituras e fichamentos, afim de compreender o surgimento de algumas cidades do estado de São Paulo, e sobre como e o porquê da difusão da arquitetura déco no Brasil.

\section{A INFLUÊNCIA DA FERROVIA E O CONTEXTO DÉCO}

A Estrada de Ferro São Paulo Railway de 1867, foi a primeira inaugurada no estado, aberta por uma empresa inglesa, seu intuito era ligar, através de uma via segura, a cidade de Santos até Jundiaí, facilitando os meios de escoamento de mercadorias entre os mesmos.

[...] a partir da segunda metade do século XIX, o sistema ferroviário em São Paulo teve um papel importante no processo de colonização e no desenvolvimento econômico do Brasil. As ferrovias possibilitaram a ampliação das fronteiras para formação de novas cidades, e serviram de suporte econômico para produção agrícola e atividades pecuárias, principalmente nos cultivos do café, que foi base da economia brasileira até meados da década de 1930. (MATOS apud FICI, 2007, p. 05).

Apesar do domínio conquistado pela ferrovia, não houve interesse de seus proprietários em realizar a prolongamento de sua malha ao interior do estado. Assim, suprindo a necessidade da burguesia paulista que aspirava o prolongamento da ferrovia, surge a Companhia Paulista, em 1870, ligando Jundiaí a Campinas, estrada que seguiu os modelos da companhia inglesa e que facilitou negócios agrícolas com a região de ligação. (MATOS, 1990).

Segundo Matos (1990), outras duas importantes companhias ferroviárias formadas entre 1870 e 1873 foram a Companhia Ituana e a Companhia Sorocabana, a primeira tinha o intuito de ligação entre Itú e Jundiaí, porém seus limites foram além, conectando em 1879 a região de Piracicaba, e em 1888 a região de São Manoel, obtendo um total de 220 quilômetros de linha.

Já a Companhia Sorocabana, estrada de influência do presente trabalho, foi aberta oficialmente em 1875, conectando São Paulo e Sorocabana. A extensão de sua linha até Botucatu, prometida pela companhia, se deu de maneira paulatina enfrentando dificuldades devido ao sinuoso traçado, porém, em 1889 seu destino foi alcançado. (MATOS, 1990).

Com o passar do tempo novas companhias ferroviárias foram surgindo, algumas foram se unindo, mas a intenção das mesmas não se alterou, sua função era totalmente voltada para o auxílio da economia cafeeira. A expansão do café atraiu ainda imigrantes de todo o mundo para seu cultivo, incentivando o crescimento de diversas cidades do interior do Brasil. "As estradas de ferro fixavam novos povoamentos e foram criadoras de novas paisagens, seguiam a expansão agrícola, além de valorizar os terrenos, estimular o desenvolvimento do comércio, serviços e atividade industrial. " (MATOS, 1990, p. 148). Continuando na mesma linha de pensamento Matos ainda descreve:

As ferrovias de São Paulo apresentaram grande viabilidade econômica, pois, além de integrar espaços, foram criadoras de paisagem, modelavam a paisagem urbana, estimulavam o crescimento econômico e constituíam um marco na história das cidades paulistas. As ferrovias provocaram a 
concentração e a valorização das terras, viabilizavam a expansão agrícola, e proporcionavam melhores facilidades para a realização de novas construções em suas áreas de influência. As estradas de ferro foram um ponto de referência de desenvolvimento e criaram a consciência da importância desse meio de transporte para o desenvolvimento regional e um exemplo para o restante do Brasil. (MATOS, 1990, p.159).

Apesar de tamanha importância para o desenvolvimento nacional, a década de 1940 retratou o fim do período ferroviário no Brasil, principalmente devido a crescente atuação do setor automotivo e pelo enfraquecimento do café (MATOS, 1990). Contudo, as consequentes marcas deixadas pelas estradas de ferro prevalecem até hoje. "As estações ferroviárias, pouco a pouco, concentraram as primeiras atividades urbanas - oficinas, armazéns e depósitos - e irradiaram os caminhos que interligavam povoados, chácaras e sítios [...]. " (PASSARELLI, 2006, p. 364).

Assim, diversos edifícios foram se fixando as margens da linha férrea, os quais foram se multiplicando com o passar do tempo, dentre eles destacam-se as numerosas construções comerciais e industrias. Se aproveitando da facilidade do transporte e escoamento de produtos, as indústrias se instalavam próximas as estações ferroviárias, com atividades exercidas em diferentes âmbitos, no geral buscavam suprir necessidades básicas da população local e circunstante.

Para tanto, os edifícios que abrigavam as funções fabris, frequentes após a década de 1930, se adotaram de uma arquitetura contemporânea para os padrões da época, prática e acessível, que caíra a gosto popular, a arquitetura de tendência Art déco.

O Art déco revelou-se uma linguagem acessível às elites, às classe médias e às classes populares. Na arquitetura, a partir de construções de maior porte, o vocabulário conquistou o gosto popular e disseminou-se em grandes e pequenas residências e em prédios comerciais. Suas linhas geometrizadas - especialmente os volumes, os vãos e as superfícies escalonadas - popularizaram-se em cidades grandes e pequenas, convertendo-se em marco do cenário urbano brasileiro das décadas de 1930 e 1940. (CORREIA, 2008, p. 54).

Segundo Correia (2008), introduzido a partir da década de 1920, o estilo déco relacionase a um conjunto de expressões artísticas presentes em diversos segmentos, como edificações, móveis, objetos, esculturas, etc., atingindo seu ápice nos anos 1930. Seu repertório formal engloba temas sugestionados por máquinas, pela flora, fauna, relacionando-se a linguagens clássicas e culturas antigas. "Um amplo conjunto de temas compõe o repertório decorativo art déco, incluindo motivos figurativos estilizados, elementos geométricos abstratos ou formas curvas aerodinâmicas." (CORREIA, 2008, p.50).

Em relação a arquitetura, a Art déco intermediou pontos do racionalismo moderno fazendo conexões com o ecletismo, influenciando-se por diferentes correntes, futurista, expressionista e cubista foram algumas delas, além das correntes e estilos arquitetônicos já produzidos anteriormente e os que acabavam de surgir, mais contemporâneos. A aparência inovadora presente no estilo deve-se a simplicidade de suas formas, concebidas por elementos geométricos, que incorporaram ainda em sua decoração e ornamentação, diferentes fontes referenciais. (CORREIA, 2008).

No Brasil, o visual déco apresentou-se em inúmeras construções, a princípio em projetos que procuravam explanar um mundo moderno, atrelado a novos programas. Assim ocorreu com os prédios que simbolizaram a transição de capitais a metrópoles; com lojas de departamento que 
apresentaram uma inovadora concepção de comércio; com obras institucionais que comportavam uso do estado que se desenvolveu e expandiu, com clubes, cinemas e emissoras de rádio, que apresentaram uma nova maneira de divertimento e cultura. Em pouco tempo o estilo se propagou, chegando a abrigar edifícios fabris, lojas, igrejas e residências. (CORREIA, 2010). A torre da estação central do Brasil (figura 01), localizada na cidade do Rio de Janeiro, é uma das obras déco mais expressivas do Brasil.

Figura 01: Estação Central do Brasil.

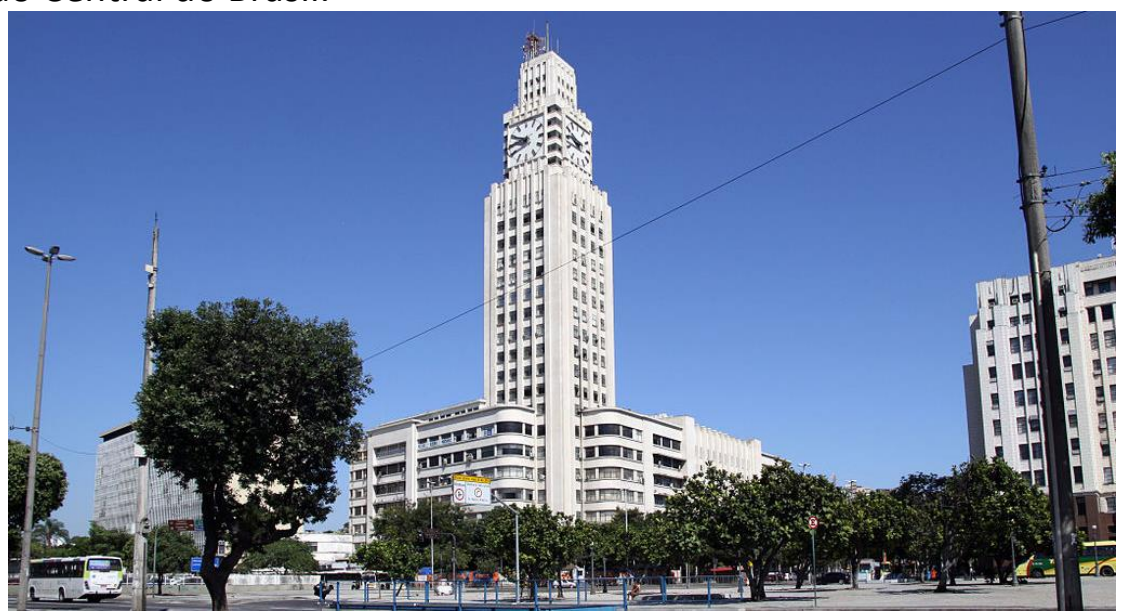

Fonte: wikipedia.org - Halley Pacheco de Oliveira (2012).

Em muitos casos, as construções referenciadas no estilo déco limitavam-se a utilizar apenas ornamentações nas fachadas, enquanto as características construtivas continuavam seguindo padrões usuais da época, relativas as técnicas propagadas no século XIX e período colonial. Por outro lado, em outras situações, o repertório art déco empregou-se em construções revolucionárias, tanto em tipologias de edificações quanto em técnicas construtivas, utilizando-se metal, concreto armado, etc. (CORREIA, 2008). A estação ferroviária da cidade de Presidente Prudente, localizada no interior do estado de São Paulo e reconstruída na década de 1940, também possui as características déco, demonstradas na figura 02 abaixo.

Figura 02: Atual estação ferroviária de Presidente Prudente.

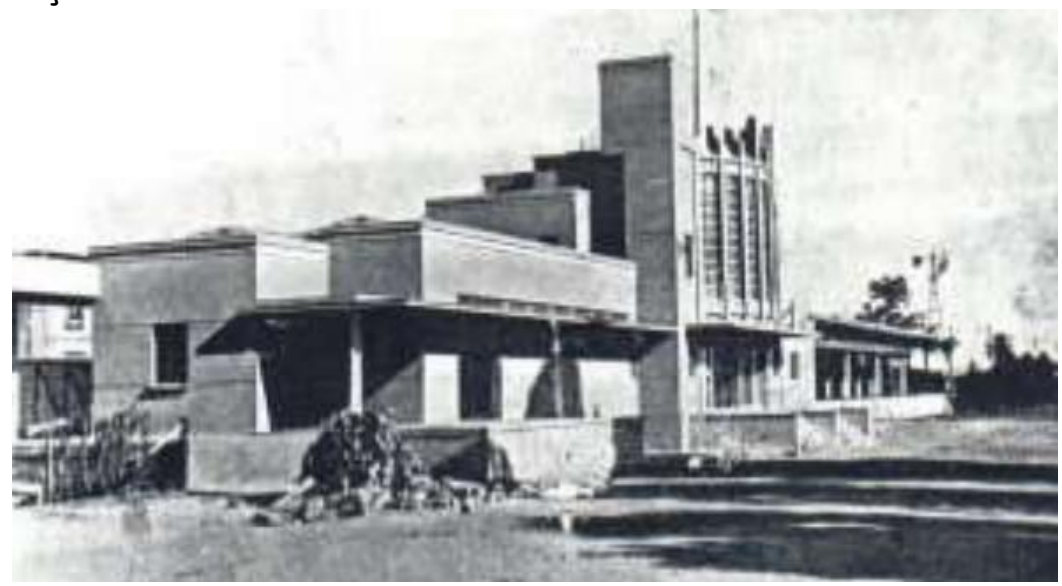

Fonte: Acervo Museu Municipal de Presidente Prudente (1944).

Dentre as características arquitetônicas da Art déco, Correia (2008) destaca a premissa da hierarquização, apresentado no realce do acesso principal e nas formas escalonadas. A edificação é estruturada pelo arranjo formal dos volumes, para tanto utilizam-se formas geométricas, como elementos arredondados, cilíndricos, retangulares, e, diferentes alturas e comprimentos. Outro 
aspecto importante, presente em muitas construções déco, é a busca da monumentalidade, obtida através da composição estratégica dos volumes, dando ênfase na altura edificada.

Entre os recursos que integraram o repertório formal do Art déco na arquitetura encontram-se: marquises; balcões em balanço; colunas, frontões, capitéis, pilastras, platibandas e volutas de formas esquemáticas; gradis e caixilhos de metal, inclusive do tipo basculante; ornatos em alto ou baixo relevo, representando formas geométricas, temas florais simplificados, linhas retas, em ziguezague, ou linhas em espirais. Os vãos surgem retangulares, circulares, escalonados ou acompanhando as superfícies curvas das quinas das fachadas. (CORREIA, 2008, p.51).

A aceitação do gosto déco no Brasil, comprova-se através de sua utilização na arquitetura fabril, a qual se difundia além das fábricas, alastrando-se para os equipamentos de uso coletivo, residências operárias, fazendo presente até mesmo em moradias de uso particular de seus proprietários. Tal fato desvenda-se pela inovação formal que o estilo abordou, bem como sua ligação com o universo industrial e percepção de modernização.

A propensão ao abstrato, a partir de diferentes volumes e ornamentos geométricos, relaciona-se ao maquinário das fábricas, produtos resultantes, e até mesmo as formas de produção, fazendo-se assim, total menção ao universo fabril. (CORREIA, 2008).

\section{CONCLUSÃO}

Conforme demonstrado, a arquitetura déco de fato se alastrou por todo o país, através de meios simples e econômicos de construção, com a alvenaria de tijolo revestida com reboco, adotando-se uma linguagem visual marcante com platibandas, formas escalonadas, ornamentos geométricos e a composição de volumes, o estilo acabou por dominar o universo fabril da década de 1930 e 1940, bem como inúmeras outras edificações da época.

Concomitantemente ao final do período ferroviário no Brasil, o que pode-se perceber é que esta arquitetura se fez presente principalmente ao redor deste meio de circulação, umas vez que através dos mesmos é que se instalaram diversos edifícios industriais, que aproveitavam-se da facilidade de circulação da ferrovia como meio de escoamento de produtos.

Desta forma compreende-se a história e características deste estilo arquitetônico que se difundiu de forma tão intensa no Brasil e no mundo, e que se encontra até os dias atuais em muitos edifícios importantes, até mesmo bairros históricos de cidadezinhas paulista.

\section{REFERÊNCIAS BIBLIOGRÁFICAS}

CORREIA, T. B. Art déco e indústria: Brasil, décadas de 1930 e 1940. Anais do Museu Paulista, São Paulo, v. 16, n. 2, 2008.

CORREIA, T. O Art Déco na arquitetura brasileira. Revista UFG, Goiânia, n. 8, p.14 - 18, 2010.

$\mathrm{FICl}$, R. P. As Ferrovias Brasileiras e a Expansão Recente para o Centro-Oeste. 2007. 339 f. Dissertação (Pós-Graduação em Geografia Humana) - Universidade de São Paulo, São Paulo, 2007.

MATOS, O. N. Café e Ferrovias - A evolução Ferroviária de São Paulo e o Desenvolvimento da

Cultura Cafeeira. 4. Ed. Campinas (SP): Pontes, 1990. 
PASSARELLI, S. H. F. Paisagem ferroviária: memória e identidade da metrópole paulistana. Exacta, São Paulo, v. 4, n. 2, p. 363-373, jul./dez. 2006.

VILLAÇA, F. Espaço Intra-urbano no Brasil. São Paulo: Studio Nobel, 2001. 